\title{
EHMTI-0084. Resting state functional connectivity abnormalities in pediatric patients with migraine
}

\author{
R Messina ${ }^{1 *}$, MA Rocca ${ }^{1}$, B Colombo ${ }^{2}$, E De Meo ${ }^{1}$, A Falini $^{3}$, G Comi ${ }^{2}$, M Filippi $^{1}$ \\ From 4th European Headache and Migraine Trust International Congress: EHMTIC 2014 \\ Copenhagen, Denmark. 18-21 September 2014
}

\section{Introduction}

Previous resting state (RS) functional magnetic resonance imaging (fMRI) studies in adult patients with migraine have demonstrated abnormal functional connectivity (FC) of brain networks involved in pain processing, including the default mode (DMN), the salience (SN) and the executive control (ECN) network.

\section{Aims}

To explore abnormalities of brain RS FC in pediatric patients with migraine and their correlation with patients' clinical characteristics.

\section{Methods}

Using a 3.0 Tesla scanner, RS fMRI scans were acquired from 13 pediatric migraine patients and 15 age-matched controls. Independent component analysis and a templatematching procedure were used to identify the DMN, ECN, working memory networks (WMN), SN, sensorimotor (SM), auditory and visual (VN) networks. Within-group and between-group RS FC comparisons and analysis of correlation were performed using SPM8.

\section{Results}

Compared to controls, pediatric migraine patients had an increased RS FC of the orbito-frontal, middle and posterior cingulate gyrus of the DMN and WMNs, the inferior temporal gyrus of the ECN, the rolandic operculum and lingual gyrus of the WMNs and the postcentral gyrus of the VN. They also experienced a decreased RS FC of the anterior cingulum of the $\mathrm{SN}$, the middle temporal gyrus and cerebellar vermis of the WMNs and the superior temporal gyrus of the SM. Altered RS FC of the temporal

${ }^{1}$ Neuroimaging Research Unit and Dept. of Neurology, Scientific Institute and University Hospital San Raffaele, Milan, Italy

Full list of author information is available at the end of the article lobes of the ECN and WMN was correlated with disease duration and attack frequency.

\section{Conclusions}

In pediatric migraine patients, distributed abnormalities of brain RS FC occur and engage not only pain-facilitating and pain-inhibiting regions, but also areas involved in executive processes.

No conflict of interest.

\section{Authors' details}

${ }^{1}$ Neuroimaging Research Unit and Dept. of Neurology, Scientific Institute and University Hospital San Raffaele, Milan, Italy. ${ }^{2}$ Dept. of Neurology, Scientific Institute and University Hospital San Raffaele, Milan, Italy. ${ }^{3}$ Dept. of Neuroradiology, Scientific Institute and University Hospital San Raffaele, Milan, Italy.

Published: 18 September 2014

doi:10.1186/1129-2377-15-S1-B22

Cite this article as: Messina et al:: EHMTI-0084. Resting state functional connectivity abnormalities in pediatric patients with migraine. The Journal of Headache and Pain 2014 15(Suppl 1):B22.

Submit your manuscript to a SpringerOpen ${ }^{\odot}$ journal and benefit from:

- Convenient online submission

- Rigorous peer review

- Immediate publication on acceptance

- Open access: articles freely available online

- High visibility within the field

- Retaining the copyright to your article

Submit your next manuscript at $>$ springeropen.com
(C) 2014 Messina et al; licensee Springer. This is an Open Access article distributed under the terms of the Creative Commons Attribution License (http://creativecommons.org/licenses/by/2.0), which permits unrestricted use, distribution, and reproduction in any medium, provided the original work is properly cited. 